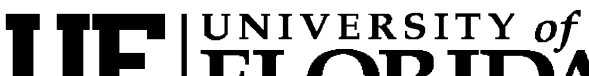 FLORIDA \\ IFAS Extension
}

ENY-150

\section{Colony Collapse Disorder (CCD) in Honey Bees ${ }^{1}$}

Jamie Ellis ${ }^{2}$

\section{Introduction}

The U.S. beekeeping industry has faced a number of obstacles to healthy bee management over the years. These obstacles range from arthropod pests to pathogenic diseases. Now a new problem threatens the beekeeping industry and it may eclipse altogether the bee maladies of old. Termed "colony collapse disorder" (or CCD), the disorder has gained considerable national and international attention.

Beekeepers around the United States have reported higher-than-usual colony losses since the fall of 2006. Some beekeepers in states reporting CCD have lost $50-90 \%$ of their colonies, often within a matter of weeks. This translates into thousands of dead colonies and millions of dead bees. In a country where honey bees contribute billions of dollars in added revenue to the agriculture industry, these bee losses cannot be taken lightly.

It has been difficult to assess the impact of CCD in the U.S. and globally. Nationally, beekeepers have been asked to complete a survey tool designed by Bee Alert Technologies, Inc. (the online version can be found at: http://www.beealert.info/). The survey tool is designed to assess the distribution and severity of CCD and to provide a means of determining what variables might be contributing to the problem. Thus far, most CCD impact data are based on anecdotal reports and early surveys provided by beekeepers. It is believed, however, that many thousands of bee colonies in the U.S. have died expressing symptoms of CCD since the fall of 2006.

CCD may not be a new disorder. In fact, many colonies have died over the past 50-60 years displaying symptoms similar to those of CCD. The disorder as described in older literature has been called spring dwindle disease, fall dwindle disease, autumn collapse, May disease, and disappearing disease. We may never know if these historic occurrences share a common cause with modern-day CCD. They do, however, share the symptoms.

\section{Colony Collapse Disorder}

Symptomatically, colonies with CCD can appear healthy as few as three weeks prior to collapse. However, the adult bees soon "disappear" (hence its historic nickname "disappearing disease") from the colonies, leaving behind a box full of honey, pollen, capped brood, a queen, and maybe a few worker bees. Beekeepers report that colonies with CCD do not

1. This document is ENY-150 (IN720), one of a series of the Entomology and Nematology Department, Florida Cooperative Extension Service, Institute of Food and Agricultural Sciences, University of Florida, Gainesville, FL. Publication date: May 2007. For more publications related to horticulture/agriculture, please visit the EDIS Website at http://edis.ifas.ufl.edu/.

2. Jamie Ellis, assistant professor, Entomology and Nematology Department, Institute of Food and Agricultural Sciences, University of Florida, Gainesville, FL 32611

The Institute of Food and Agricultural Sciences (IFAS) is an Equal Opportunity Institution authorized to provide research, educational information and other services only to individuals and institutions that function with non-discrimination with respect to race, creed, color, religion, age, disability, sex, sexual orientation, marital status, national origin, political opinions or affiliations. U.S. Department of Agriculture, Cooperative Extension Service, University of Florida, IFAS, Florida A. \& M. University Cooperative Extension Program, and Boards of County Commissioners Cooperating. Larry Arrington, Dean 


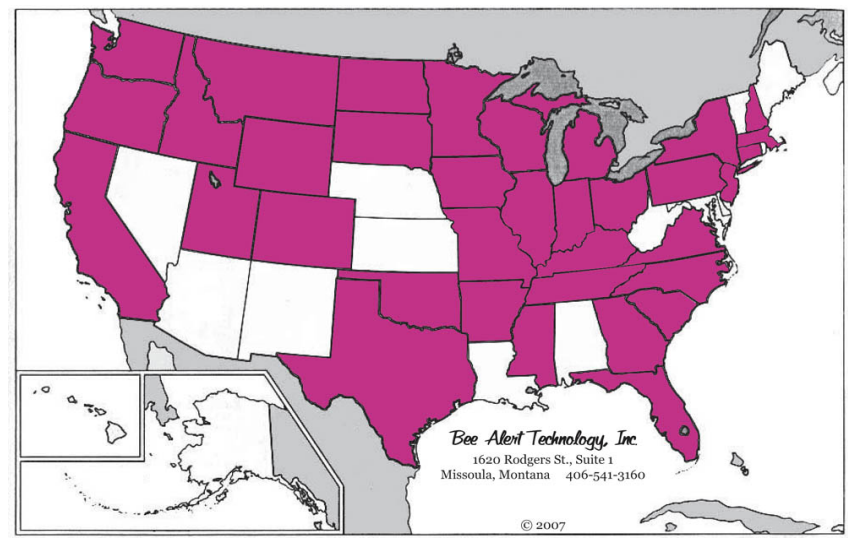

Figure 1. States where beekeepers reported significant honey bee losses to Colony Collapse Disorder as of April, 2007. Credits: Bee Alert Technology, Inc.

contain any dead bees, neither are there dead bees on the ground outside of the colonies. The adult bees simply vanish. The final symptom is that small hive beetles, wax moths, and other nearby honey bees ignore the empty hives even though the hives contain foodstuffs on which they ordinarily feed.

The Mid-Atlantic Apiculture Research and Extension Consortium (MAAREC: http://www.ento.psu.edu/MAAREC/index.html) is the current clearing house for CCD-based information produced by the CCD Working Group. Composed of scientists, beekeepers, industry, and government officials, the CCD Working Group defined the symptoms of CCD as follows:

\section{Collapsed colonies}

1. complete absence of adult bees in colonies, with few or no dead bees in or around colonies,

2. the presence of capped brood, and

3. the presence of food stores (both honey and bee bread) that are not robbed by other bees or typical colony pests (small hive beetles, wax moths, etc.). If robbed, the robbing is delayed by a number of days.

\section{Collapsing colonies}

1. an insufficient number of bees to maintain the amount of brood in the colony,

2. the workforce is composed largely of younger adult bees,
3. the queen is present, and

4. the cluster is reluctant to consume food provided to them by the beekeeper.
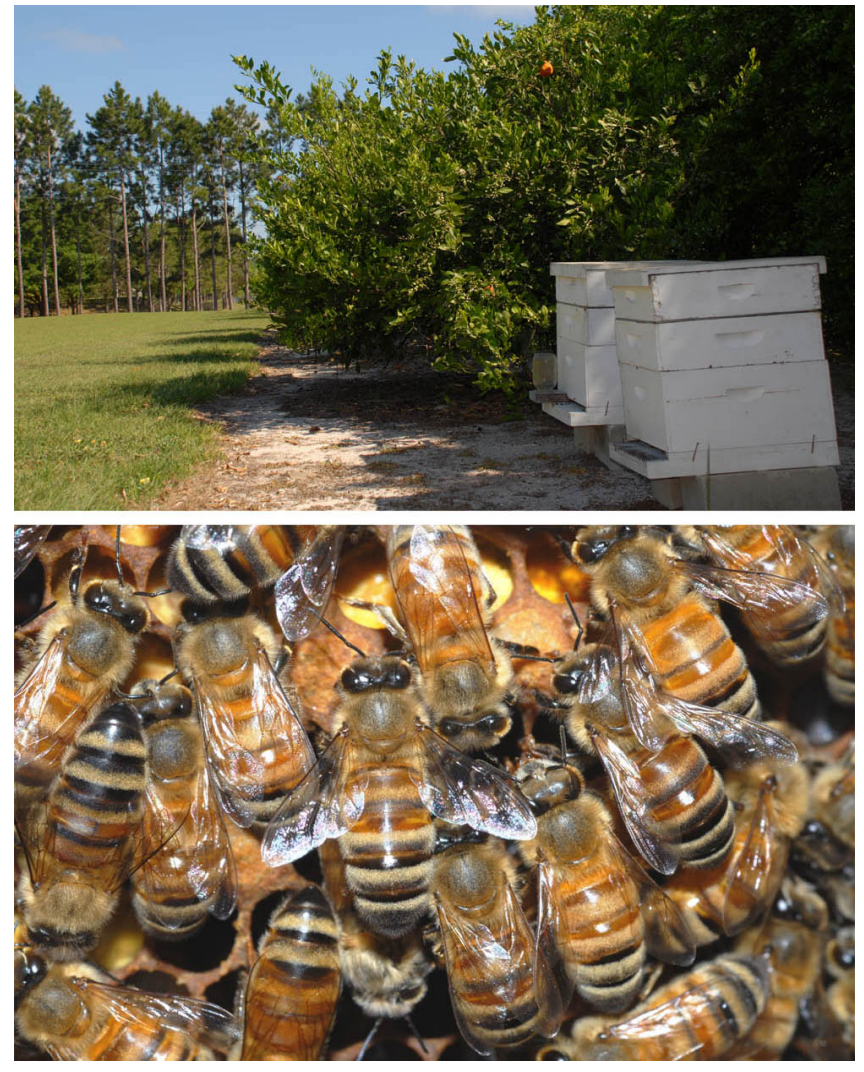

Figure 2. Healthy colonies of bees (a) contain thousands of worker bees (b). Colonies suffering from Colony Collapse Disorder have few or no bees remaining in the hive. Credits: Sean McCann, University of Florida

\section{What Causes Colony Collapse Disorder?}

The cause of CCD is under investigation. At this point, almost every conceivable and realistic cause remains a possibility. The leading candidates and a brief explanation of their potential role are listed below. This is not a comprehensive list and the candidates occur in no particular order. It is important to note that this list may change as new information on CCD becomes available. Such changes could result in the addition or exclusion of any of the following potential causes. The author makes no attempt to promote or undermine any one of the following theories.

\section{Traditional bee pests and diseases (including} American foulbrood, European foulbrood, chalkbrood, nosema, small hive beetles, and 
tracheal mites): Although considered potential causes, "traditional" bee maladies (those nearly-cosmopolitan throughout the U.S. and globally) likely are not responsible for causing CCD. This is because they do not have a history of promoting CCD-like symptoms. That said, traditional bee pests and diseases may exacerbate the disorder, so scientists have not abandoned experiments investigating them.

2. Style of feeding bees and type of bee food: The style of feeding bees and types of bee food used to feed bees vary considerably among beekeepers reporting CCD losses. As such, no correlation has been found between what colonies were fed and their likelihood of survival. Despite this, many beekeepers have abandoned the practice of feeding high fructose corn syrup to bees due to indications that it can form byproducts that are harmful to bees.

\section{How the bees were managed: Management} style is a broad category but it can include the type of income pursued with bees (honey production, pollination services, etc.) or what routine colony management beekeepers perform (splitting hives, swarm control, chemical use, etc.). Both of these vary considerably among beekeepers so this possible cause of CCD is given less attention. That said, poor management can make any colony malady worse.

4. Queen source: Scientists are investigating the lack of genetic diversity and lineage of bees, both related to queen quality, as possible causes of CCD. Regarding the former, relatively few (in the hundreds) breeder queens are used in the U.S. to produce the millions of queen bees (and therefore all bees) used throughout the U.S. Geneticists refer to this as a genetic bottle neck. This lack of genetic biodiversity can make bees increasingly susceptible to any pest/disease that invades the system.

5. Chemical use in bee colonies: Like farmers in other agricultural sectors, beekeepers often attempt to chemically-control the various maladies affecting their honey bees in an effort to keep their bees healthy and productive. Investigators recently have found a number of sub-lethal effects of these chemicals on honey bees (workers, queens, and drones) even when the chemicals were used according to label and in accordance with best management practices suggested by specialists. These sub-lethal effects have led some to consider the role of in-hive chemical use in the CCD paradigm.

6. Chemical toxins in the environment: Another chemically-oriented theory is that toxins in the environment are responsible for CCD. Because pesticides are used widely in cropping systems in an effort to kill herbivorous insects, one is left to consider the potential for non-target chemical effects on foraging bees. In addition to being exposed to toxins while foraging, honey bees also may encounter toxins by drinking water contaminated with chemical runoff, encountering various chemicals (household, commercial, etc.) through contact outside of the hive, or via direct inhalation.

7. Genetically modified crops: Some people have proposed that genetically modified crops may be responsible for the widespread bee deaths. Interestingly, many seeds from which genetically modified crops are grown are dipped first in systemic insecticides that later may appear in the plants' nectar and pollen. This makes genetically modified plants suspect because of their chemical treatment history, not just because they are genetically modified. Scientists have begun initial investigations into both theories but no conclusive data have been collected.

\section{Varroa mites and associated pathogens: Even} with the concerns surrounding $\mathrm{CCD}$, varroa mites remain the world's most destructive honey bee killer. As such, varroa and the viruses they transmit have been considered as possible causes of CCD. Further, varroa often are controlled chemically by beekeepers. So varroa (perhaps not directly) has been considered a potential cause of CCD because the mite itself is damaging, it transmits viruses to bees, and it can elicit chemical responses from beekeepers. Despite this, there have been instances of colonies showing symptoms of CCD when their varroa populations were under control. 
9. Nutritional fitness: Scientists have proposed nutritional fitness of adult bees as a potential cause of CCD. This topic is being investigated although little information exists currently to support/refute the role of nutrition. Malnutrition is a stress to bees, possibly weakening the bees' immune system. A weak immune system can affect a bee's ability to fight pests and diseases.

\section{Undiscovered/new pests and diseases:}

Finally, undiscovered or unidentified pests/pathogens are considered possible causes of CCD. Some believe that a new pest/disease may have been introduced into the U.S. and is causing CCD. To give one example, Nosema apis (a microsporidian that lives in the digestive tract of honey bees) has been present in the U.S. for many years. In 2006, scientists discovered and identified a new nosema species, Nosema ceranae, present in some colonies displaying symptoms of CCD (it also has been found in bee samples dating back to 1995). When this disease is present in bees in elevated levels, the bees leave their colonies, never to return. Although the role of $N$. ceranae in the CCD complex is not understood, it and other new pathogens may play an important role in elevated bee deaths.

Many scientists believe that CCD is caused by a combination of the factors above. To illustrate this point, some dead bees showing symptoms of CCD have had elevated levels of normally-benign pathogens in their bodies, possibly indicating a compromised immune system. In theory, any stress or combination of stresses (chemicals, genetic bottlenecks, varroa, etc.) can suppress a bee's immune system. Considering synergistic effects as a potential cause of CCD makes the disorder increasingly harder to study.

\section{How Will Colony Collapse Disorder Affect the General Public?}

In general, most people respect honey bees, recognizing their importance, while being cautious when near them. This is not surprising because honey bees can inflict a painful sting. Stings aside, most people also recognize honey bees for the sweet honey that they produce. To be sure, the production and sale of honey supports thousands of beekeeper families and provides the consumer with an alternative to sugar (incidentally, there is no evidence that honey from CCD colonies is unsafe for human consumption). However, honey is of only minor importance compared to the benefits afforded humans by honey bee pollination.

Beekeepers managing their bees for purposes of pollination load their colonies on trucks and move them around the country, going from blooming crop to blooming crop. Growers pay beekeepers from \$40-150 per colony just to ensure that they will have an adequate supply of honey bees to pollinate their crop. In return, the growers benefit by having a higher fruit/vegetable/nut production per acre, larger size and better shape of the product, and even enhanced product taste in many instances.

The benefits of honey bee pollination are not to be taken lightly. The simple act of beekeepers moving honey bees around the country ensures our country's food supply. Agriculture needs honey bees and their disappearance is cause for concern. Yet, no one believes that honey bees will disappear altogether, even with the concerns over CCD. Instead, the average American may experience increased food prices and decreased food availability if honey bees continue to die at the current rate. The almond industry illustrates this point well.

Almond producers in California continue to plant more acres of almonds every year yet honey bee populations have suffered a steady decline during the same time period. The latest estimation suggests that by 2010 , California almonds will need every honey bee colony in North America just to be pollinated adequately. If all of the bees are going to California for almond pollination, what will happen to apples in Washington? Blueberries in Maine? Citrus in Florida? Etc.? This loss of bees could begin a price war in the pollination industry, resulting in growers being forced to pay higher rent prices for bee colonies. The net effect is that the consumer will have to pay a higher price for the food that they currently enjoy. In the worst case scenario, food availability will begin to decrease as honey bees die. 
The benefits of honey bees are undeniable and often under-appreciated. Because CCD has initiated a rapid loss of colonies in the U.S. and globally, the general public should be alarmed. Perhaps the worst thing to come from all of this is that the loss of bees could signal a decline in the health of our environment. Honey bees are biological indicators, meaning that their status is a reflection of the health of the general environment. If true, bee losses may be the beginning of a much larger environmental issue.

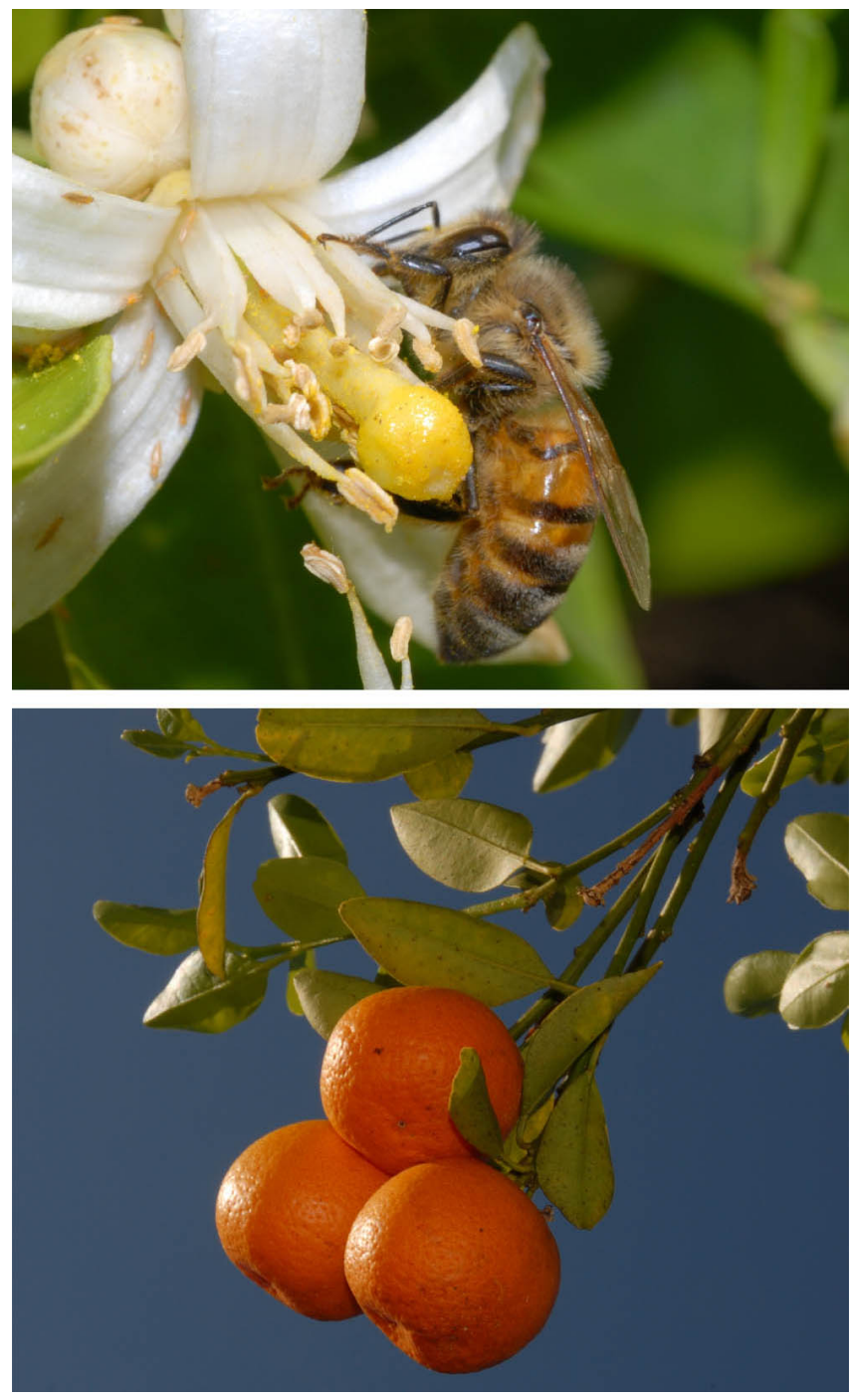

Figure 3. Honey bees are important pollinators of the nation's crops. Pollen adheres to bee's bodies when they visit flowers (like this citrus flower in picture a). As they go from flower to flower, they transport the pollen between flowers, thus pollinating the flower. Flowers that are adequately pollinated produce fruit (b), vegetables, or nuts. Higher fruit set, larger fruit, uniformly-shaped fruit, and better taste are all indications of successful pollination. Credits: Sean McCann, University of Florida

\section{What is Being Done?}

In the past, most of the work on CCD has been conducted by those affiliated with the CCD Working Group. That is changing as more scientists are beginning to investigate various avenues of CCD. Beekeepers, governmental officials, and scientists from universities, industries, and the USDA have initiated a number of investigations into the possible causes of CCD. At this point, it is safe to assume that most potential causes of CCD are being investigated. In addition to this, many granting agencies realize the importance of honey bees and have begun to distribute research funds in an effort to find the cause and a cure.

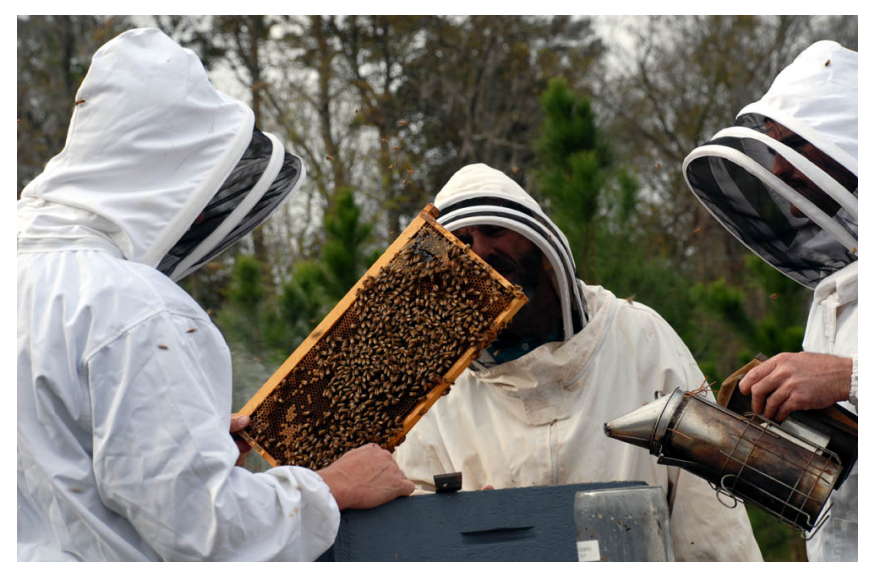

Figure 4. Scientists are trying to determine the source of Colony Collapse Disorder. Credits: Sean McCann, University of Florida

\section{What can Beekeepers do to Avoid Colony Collapse Disorder?}

(Modified from recommendations made by the CCD Working Group)

Because CCD is not well-understood, the CCD Working Group has made the following recommendations in an attempt to give beekeepers some control options.

- Do not combine collapsing colonies with otherwise healthy ones - the cause of CCD has not been identified so it is possible that combining a sick colony with a healthy one will "contaminate" or "infect" the healthy colony.

- If you find abandoned hive equipment and the cause of bee death is suspicious, store the equipment in a manner that prohibits other bees 
from accessing it. Do not let neighboring colonies rob out equipment that has hived collapsed colonies. Do not reuse the equipment if the colony displayed symptoms of CCD. Such equipment should be stored securely until CCD is understood better.

- Feeding bees fumagillin in sugar water in spring and fall should be considered by all beekeepers. Although nosema (Nosema apis) is not considered the causative agent of CCD, investigators have found Nosema ceranae in some bee colonies in the U.S. Both can be considered stressors that may promote CCD.

- If you ordinarily treat with an antibiotic to prevent/control American or European foulbrood, use Terramycin rather than Tylan. Tylan has been approved only recently for use in bee colonies and it does not have a long track record. Unless foulbrood resistant to Terramycin is encountered, one should use Terramycin because it has a longer history of use in bee colonies.

- Use an Integrated Pest Management (IPM) approach for varroa control in honey bee colonies. This approach can minimize the need for chemical use in bee colonies, lessening bee exposure to potentially-toxic chemicals. If varroa are a problem, use approved miticides rather than off-label home remedies.

- Keep colonies strong by practicing best management practices.

Please contact your county extension agent if you have any questions regarding $\mathrm{CCD}$, honey bees, or beekeeping in general.

\section{Selected Reference}

There is a lack of refereed publications on CCD because (1) it is new and (2) it is not wellunderstood. Bee Alert Technology, Inc.'s and MAARECs websites (below) contain the most up-to-date information on CCD. Regardless, many news articles, videos, newsletters, etc. concerning CCD exist on the world wide web. A search for "colony collapse disorder" will yield more than 400,000 links.
Bee Alert Technology, Inc.:

http://beealert.blackfoot.net/ beealert/index.php

Mid-Atlantic Apiary Research and Extension Consortium:

http://www.ento.psu.edu/MAAREC/index.html 